\title{
The performance effects of composition changes on sector specific stock indices: The case of European listed real estate
}

Article

Accepted Version

Brooks, C., Kappou, K., Stevenson, S. and Ward, C. (2013) The performance effects of composition changes on sector specific stock indices: The case of European listed real estate. International Review of Financial Analysis, 29. pp. 132-142. ISSN 1057-5219 doi: https://doi.org/10.1016/j.irfa.2013.04.002 Available at https://centaur.reading.ac.uk/33971/

It is advisable to refer to the publisher's version if you intend to cite from the work. See Guidance on citing.

Published version at: http://www.sciencedirect.com/science/article/pii/S1057521913000483

To link to this article DOI: http://dx.doi.org/10.1016/j.irfa.2013.04.002

Publisher: Elsevier

All outputs in CentAUR are protected by Intellectual Property Rights law, including copyright law. Copyright and IPR is retained by the creators or other copyright holders. Terms and conditions for use of this material are defined in the End User Agreement.

www.reading.ac.uk/centaur 
Central Archive at the University of Reading

Reading's research outputs online 
NOTICE: this is the author's version of a work that was accepted for publication in the International Review of Financial Analysis. Changes resulting from the publishing process, such as peer review, editing, corrections, structural formatting, and other quality control mechanisms may not be reflected in this document. Changes may have been made to this work since it was submitted for publication. A definitive version was subsequently published in the International Review of Financial Analysis, 29 (2013), DOI: 10.1016/j.irfa.2013.04.002 
The Performance Effects of Composition Changes on Sector Specific Stock Indices: The Case of European Listed Real Estate*

Chris Brooks ${ }^{\dagger}$, Konstantina Kappou ${ }^{\ddagger}$, Simon Stevenson ${ }^{\S} \&$ Charles Ward ${ }^{* *}$

The Performance Effects of Composition Changes on Sector Specific Stock Indices: The Case of European Listed Real Estate

\footnotetext{
* Acknowledgements: We thank EPRA for funding this research and for providing a list of index composition changes.

'ICMA Centre, University of Reading

ICMA Centre, University of Reading

${ }^{\S}$ Corresponding Author: Henley Business School, University of Reading, Whiteknights, Reading, RG6 6AW, United Kingdom. e-mail: s.a.stevenson@ reading.ac.uk

${ }^{* *}$ ICMA Centre, University of Reading
} 


\begin{abstract}
This paper examines the impact of changes in the composition of real estate stock indices, considering companies both joining and leaving the indices. Stocks that are newly included not only see a short-term increase in their share price, but trading volumes increase in a permanent fashion following the event. This highlights the importance of indices in not only a benchmarking context but also in enhancing investor awareness and aiding liquidity. By contrast, as anticipated, the share prices of firms removed from indices fall around the time of the index change. The fact that the changes in share prices, either upwards for index inclusions or downwards for deletions, are generally not reversed, would indicate that the movements are not purely due to price pressure, but rather are more consistent with the information content hypothesis. There is no evidence, however, that index changes significantly affect volatility of price changes or their operating performances as measured by their earnings per share.
\end{abstract}

Keywords: index effect, passive funds, arbitrage, real estate indices, information content hypothesis 


\section{1: Introduction}

The index effect has become an increasingly widely known phenomenon over the last 25 years, primarily due to an increase in both the numbers and assets under management of passive index funds. This has made index composition of importance not only in the context of the investment strategies of passive funds but also because of the broader impact that the inclusion or exclusion of a stock from an index has upon its share price.The index effect can be defined as the impact that index re-composition changes have on the prices of the underlying stocks. The existence of "passive" funds that aim to track the performance of an index will ensure that demand for the stocks of firms entering the index will rise but it will fall for any stocks deleted from the index. Noting this repeated pattern of behaviour, arbitrageurs have found ways to earn profits by buying (selling) the stocks of added (deleted) firms before index funds make their trades and then selling them (buying them back) when index funds have completed their transactions. ${ }^{1}$

Whilst a large literature has developed to consider the effect in the terms of mainstream indices, and especially the S\&P 500, there has been very little to have considered more specialist benchmarks. Given that a reduced number of passive funds may track more specialist indices, it provides an interesting research question as to whether the index effect is reduced in such a context and thereby effectively limited to being of relevance in the context of the main benchmark indices only. It is this issue that this paper aims to consider using the example of European real estate securities. Over the course of the last decade, the European listed real estate sector has grown considerably, by June 2011 totalling 830 real estate stocks with an aggregate market capitalisation of $€ 321.1 \mathrm{bn}$, equating to $24 \%$ of the global listed property market. This growth has been driven by a number of key elements, none more so than the performance of the sector during the first half of the last decade. In comparison to mainstream equities, listed real estate, in both their REIT (Real Estate Investment Trust) and corporate form, delivered substantial outperformance. This, inevitably, led to increased investor awareness during a period of relatively poor stock market performance. The fact that this strong performance was not only observed in Europe but globally, added to the increased interest in the sector. In addition, particularly within a European context, the introduction of REIT regimes in the majority of the major European markets further increased investor awareness. $^{2}$ These factors have had a wide range of impacts, including increased trading volumes and, key in the context of this study, an increase in dedicated funds. Enhanced awareness of and allocations held to real estate securities have therefore also led to an increase 
in the visibility and importance of dedicated real estate security indices. Whilst obviously the primary purpose of such indices is their use in a benchmarking context, other factors also come into play. For example, in October 2007 NYSE-LIFFE-Euronext introduced two index futures contracts based upon the FTSE ERPA/NAREIT Europe and FTSE EPRA/NAREIT Eurozone indices (Lee et al., 2012).

This paper therefore expands upon the limited literature to have considered the index effect in the context of sector specific indices. Even in the context of listed real estate there is a marked lack of existing empirical evidence, and in addition, these papers have solely considered the US REIT market. Ambrose et al. (2006) considered the impact of the change in policy in 2001 that facilitated the inclusion of REITs into mainstream S\&P indices. However, the primary focus of the study was the longer term impact on REITs and specifically their relationship with the overall market. The study provided evidence that the beta of those REITs included in the S\&P 500 saw a significant upward movement, indicating increased co-movement with the overall market. Furthermore, the beta of indexed REITs with reference to a portfolio of non-indexed REITs showed virtually no change. Additional examination showed that the beta of non-index REITs also increased significantly with respect to the S\&P 500. This would imply a sectorwide impact and not one limited to those specific firms included in the S\&P indices. The study of Feng et al. (2006) is of more direct relevance and broadly follows the methodological framework adopted in the mainstream finance literature. The paper considers the price impact of additions and deletions of REITs into the dedicated S\&P REIT Index. The results reveal a small yet significant price response to index inclusions. This is of interest given that the index considered is sector specific. However, whilst a significant price response is observed, no such findings are reported with respect to trading volume or institutional investment.

This paper considers a number of key research issues, focusing on the EPRA (European Public Real Estate) family of indices. ${ }^{3}$ Firstly, we examine the impact of index composition changes in the short-run. This analysis considers the impact of changes in the constituents on not only the stock prices of the affected firms but also their trading volume and volatility. A key element in this analysis is testing for any asymmetrical impacts with respect to any possible differential response for index inclusions and deletions. The paper also considers whether there is evidence of a size effect, the impact on operating performance and if the response differs across markets. Finally, we consider the long-run impact of index changes. The remainder of the paper is organised as follows. Section 2 briefly reviews the theory and hypotheses that 
underlie the body of empirical work to have examined the index effect. Section 3 describes the data and methodological framework adopted in the study. Section 4 presents and analyses the results, while Section 5 summarises and offers some concluding comments.

\section{2: Hypotheses behind the Index Effect}

This section briefly reviews the theoretical literature on the index effect and summarises the expected impacts that additions to or deletions from an index will have on the stocks concerned. The majority of studies to have considered the issue have focused on the S\&P 500 . This is not only because the level of assets tied to this index is much greater than for any other, but also because it has a more "vague" announcement policy that does not rely only on publicly available and observable measures; thus changes in the composition of the index cannot be easily predicted. Deletions from the index are usually caused by an event (e.g. merger, takeover or bankruptcy) that subsequently requires the selection of a replacement stock. When index changes are largely unpredictable, as they are for the S\&P500, the method of announcement of such changes becomes important. S\&P pre-announce the changes a variable number of days (on average around five) before the actual new composition of the index takes place.

In the case where the re-composition criteria are clear, analysts can predict those changes in advance (see the FTSE or MSCI criteria, for example) and the event periods are not so significant, either statistically or economically, for the added or deleted stocks. The announcement and decision policy for the indices of interest for this study are laid out in the document, "Ground Rules for the Management of the FTSE EPRA/NAREIT Global Real Estate Index Series, Version 4.9 - September 2011." The index committee examines data from the last business day of February, May, August and November, and then meets on the Thursday after the first Friday of March, June, September and December to agree any index changes, which then become effective on the third Fridays of those months.

It is clear that the inclusion decision for the EPRA indices is based on size and other objective factors rather than being based on secret judgements behind closed doors as is the case for the S\&P indices. As such, we would not expect a big jump in prices, either upwards for additions or downwards for deletions, as the announcements should in the main reflect market expectations. Therefore, there should be gradual movements in prices before the event unless index replicators ignore prior information and still wait until the event date in order to minimise their tracking errors. 
Previous literature has suggested five different hypotheses to justify the index effect, depending on whether the price and volume effects are temporary or permanent. The studies below refer to the $\mathrm{S} \& \mathrm{P}$ index effect, which is significant until the present day, with price increase, upon index inclusion, that have ranged between 3\% and 8\%. The S\&P 500 index effect has been more pronounced recently, due in part to the increase of assets held in index funds. The results also vary because of the differing length of event windows chosen, the specific methodology, the level of indexed assets at the time each study was conducted and the different assumptions for what constitutes the short or long run.

The Price Pressure Hypothesis (PPH):After the event period, any abnormal return is expected to reverse fully and to reflect the long-term equilibrium price. The effect on trading volumes should closely resemble the price effect. Harris and Gurel (1986), Woolridge and Ghosh (1986), Lamoureux and Wansley (1987), Lynch \& Mendenhall (1997), and Malkiel and Radisich (2001) support the concept of temporary price pressures after inclusion.

\section{The Imperfect Substitutes and the Downward-Sloping Demand Curve for Stocks} Hypothesis(DSH):Stocks belonging to the index do not have perfect substitutes and have downward-sloping demand curves. Prices will therefore change to eliminate any excess demand in the market and hence no reversal is expected in the long-term. Abnormal trading activity should be temporary, until the new level of price equilibrium is reached. Shleifer (1986) and Wurgler and Zhuravskaya (2002) support the DSH. Morck and Yang (2002) also found that S\&P 500 membership was associated with significantly higher valuations of member firms.

The Liquidity Cost Hypothesis ( $\mathrm{LCH}$ ): Inclusion should enhance the liquidity of the underlying stock and therefore lead to a permanent increase in the stock's liquidity. Prices and trading volumes should both increase permanently. Mikkelson and Partch (1985), Edmister et al. (1996), Erwin and Miller (1998) argue in favour of the LCH.

\section{The Information Content Hypothesis and the Certification of an Index Member (ICH):After} inclusion, an important piece of information is revealed that should have a permanent effect on prices and a temporary effect on volume. Dhillon and Johnson (1991), Jain (1987) and Kappou et al. (2008 and 2010) find evidence supportive of the ICH. 
The Market-Segmentation and Investor Recognition Hypothesis (IRH):Investors know of only a subset of all stocks and just hold the stocks that they are aware of. Inclusion alerts investors to the existence of a specific stock, but they cannot become unaware of a deleted stock (at least not initially, although they may gradually forget about it), therefore the effects should not be symmetrical between additions and deletions. Chen et al. $(2002,2004)$ have supported the IRH.

In addition to index tracking, an equally important factor is the announcement policy. Index committees have reconsidered their methods of announcement of index changes, due to concerns about the price and volume pressures that could occur around the event period. The more money tied to an index, the more important the announcement policy. Since 1989, the S\&P index committee has allowed a window of five days on average between announcement and event, to alleviate price pressures caused by active traders who were trying to make money from index fund managers. Index Fund managers had to trade specific stocks on specific dates and times, for the purposes of a perfect index replication. Beneish and Whaley (1996) tested the effects of changing the S\&P announcement policy.

\section{3: Data and Methodological Framework}

The core data used in this paper consists of the relevant information for all stocks that were added to or deleted from the EPRA indices from 31 December 1999, when many indices were launched, until 25 November 2011. This paper considers a variety of EPRA indices which are examined in this study, including both country specific and continent wide benchmarks. We include index re-compositions from Belgium, Denmark, Finland, France, Germany, Ireland, Italy, the Netherlands, Norway, Portugal, Spain, Sweden, Switzerland, and the UK. The indices that we examine are the EPRA Europe Index, the EPRA Europe Liquid 40 Index, the AIM Index (UK), and the EPRA Global Index. It should also be noted that EPRA allow both REITs and property companies to enter their indices. We focus only on index changes and exclude from the analysis any corporate events that do not involve entering or leaving an index, such as delisting, mergers, rights issues, etc.

Data on stock prices, daily trading volumes, market values and earnings per share, were all obtained from Datastream. All of the analysis was conducted in local currency. Due to the international nature of the sample we adopt two alternative indices as benchmarks. The first is the FTSE EPRA/NAREIT Global Developed Market Index in order to capture global 
movements in real estate firms. The second is the S\&P 500. Whilst this initially may appear a strange choice, it provides a number of counter points to the aforementioned FTSE/EPRA/NAREIT index. Firstly, as a non-European index it provides a benchmark that none of the firms analysed are potential constituents of. Secondly, by being a non-real estate index it deepens the analysis and benchmarks the firms against the broader equity market.

We employ total return indices rather than stock prices throughout, which capture dividends paid and allow for stock splits and rights issues. Following the removal of any companies where the requisite data were not available from Datastream, we were left with 366 additions and 37 deletions in the sample pooled across all countries and indices. The imbalance in the addition and deletion samples can be explained by reference to the methodology used in the construction of the indices. The indices, and therefore their composition, are at least partly based upon minimum market capitalisation figures. This is unlike indices such as the S\&P 500 or FTSE 100 which are based upon a set number of firms ${ }^{4}$. The majority of EPRA indices have no stated maximum number of constituents, leading to an in-built bias towards additions in comparison to deletions. The exception in this regard is the Liquid 40 Index.

This sample makes up our main sample for the baseline regressions, although we also examine countries separately where the remaining number of companies is sufficiently large to be able to conduct a reliable analysis. It is important to note that some firms enter multiple indices and therefore they will be included in our database more than once. This is important since it allows us to fully capture the index effect for all companies and it is sometimes the case that they enter the various indices at different points in time. Therefore a given firm's price, volume etc. may display different behaviour depending on the index that it enters and the timing of the event.

Changes in the composition of indices have generally been examined through the use of standard event study methodology. Previous researchers have mainly used the simple model where an abnormal stock return is determined by the difference of the stock return and the index return on a given date, or have used the single index model, where the market risk factor (beta sensitivity) is also included. Such approaches subtract out (using varying techniques) the impact of general market-wide movements on the returns to hone in on the pure impact of company-specific events. Kappou, Brooks \& Ward (2010) also used the Fama-French 3-factor model in order to account for size and book to market effects. However, we do not subtract 
away the returns due to size and style using this approach for two reasons. Firstly, it is debateable whether this kind of performance attribution is relevant to listed real estate as the majority of real estate securities will display the broader characteristics of value stocks. In addition, only a small proportion of firms can be classified as large cap. Secondly, we prefer to capture the impact of size more directly by splitting the sample of companies by their market capitalisations.

Previous studies have used a variety of different approaches for calculating abnormal returns during the event window. However, the most common method adopted is the single-factor model, incorporating market risk. Estimates of the alpha and beta coefficients can be obtained using a historic estimation period. However, Jain (1987) and Edmister, Graham and Pirie (1994 and 1996) argue that the parameter estimates derived from the period before the event would be biased since the firms were likely to have performed well prior to their inclusion in the index. In other words, they might well have been included in the index precisely because of their relatively good recent past performance. We therefore employ a post-event period of 250 trading days together with the single index model to calculate REIT betas and thus to control for market-wide movements. In the regression analysis below, the variables are defined as follows: $R_{i t}$ is the return on firm $i$ at time $t, R_{m t}$ is the return on the market index, which is the value-weighted return on all stocks in the EPRA or S\&P500 benchmark, $a$ is the return when the factor portfolio returns are zero, $b_{m}$ is the sensitivity to market risk, and $u_{t}$ is a disturbance term. The single index model is specified as follows for each firm $i$ at time $t$ :

$$
R_{i t}=a+b_{m} R_{m t}+u_{t}
$$

The abnormal return for each stock will thus be given by:

$$
A R_{i t}=R_{i t}-\left[\hat{b}_{m} R_{m t}\right]
$$

The abnormal returns for all stocks are then averaged against the total number of additions or deletions $N$ for each day $t$ of the event window as:

$$
A A R_{t}=\frac{1}{N} \sum_{i=1}^{N} A R_{i t}
$$


where, $t=t-5$ to $t+15$ for the short-term event window, and $t=t-5$ to $t+180$ for the long-term event window. The average abnormal returns are summed over the event window in order to obtain a cumulative average abnormal return $C A A R_{I, T}$ for each time period from day $I$ to $T$.

$$
C A A R_{I, T}=\sum_{t=I}^{T} A A R_{t}
$$

To test the statistical significance of the AARs and CAARs, two-tail $t$-tests are performed that are defined as follows. For testing AARs:

$$
t-s t a t=\frac{A A R_{t}}{\hat{\mathrm{S}}\left(A A R_{t}\right)}
$$

where $A A R_{t}$ is the average abnormal return at time $t, t=t-5$ to $t+15$ for the short-term event window and $t=t-5$ to $t+180$ for the long-term event window, $\hat{\mathrm{S}}\left(A A R_{t}\right)$ is the standard deviation of the average abnormal returns over the estimation period ( 250 trading days), given by the following formula:

$$
\hat{\mathrm{S}}\left(A A R_{t}\right)=\sqrt{\frac{1}{249} \sum_{t=1}^{250}\left(A A R_{t}-\overline{A A R_{t}}\right)^{2}}
$$

For testing the $C A A R$ :

$$
t-s t a t=\frac{C A A R_{I, T}}{\hat{\mathrm{S}}\left(A A R_{t}\right) \sqrt{n}}
$$

where, $C A A R_{I, T}$ is the cumulative average abnormal stock return from day $I$ to $T$ and $n$ is the number of days between $I$ and $T$. The null hypothesis is that the AARs and CAARs should be zero $^{5}$.

We also examine volume patterns before, during and after addition. Volume data can give important information about the timing of purchases by index funds and other institutional investors, as well as demand that might have been caused by arbitrageurs. Index funds might choose to wait for the event date in order to minimize their tracking errors, even if this means 
that they end up paying more for newly included stocks or have to sell the deleted ones for lower prices. In order to calculate the level of abnormal volume, volume ratios were computed, a method also employed by Harris and Gurel (1986) and by Beneish and Whaley (1996). ${ }^{6}$ The average relative stock-to-EPRA Index volume ratios were estimated over a period of 12 weeks (60 trading days) before the event window, considered and compared with the daily stock-to index ratios observed during and after the event period ${ }^{7}$.The null hypothesis is that the mean volume ratio across all firms for each day $t$ of the event period is one. The formulae for calculating volume ratios are:

$$
\begin{aligned}
& \overline{B V R_{i}}=\frac{1}{60} \sum_{t=A D-65}^{t=A D-5}\left(\frac{V_{i t}}{V_{m t}}\right) \\
& V R_{i t}=\frac{V_{i t}}{V_{m t}} \div \overline{B V R_{i}} \\
& M V R_{t}=\frac{1}{N} \sum_{i=1}^{N} V R_{i t}
\end{aligned}
$$

where the base relative volume ratio $B V R_{i}$ is the average stock-to-index trading volume in the 12 weeks before the start of the event window, $V_{i t}$ and $V_{m t}$ are the trading volume of each stock and the corresponding benchmark volume on each day $t$ of the event window respectively, $M V R_{t}$ is the mean volume ratio across firms on each day $t$ of the event window and $N$ is the number of firms in the sample.

\section{4: Results}

\section{1: The Index Effect on Returns}

Table 1 presents the results for the sample of additions, pooled across countries and indices, over the event window from day $t-5$ to day $t+15$. The final five rows display the cumulative returns for the pre- and post-event windows, and also for a long-run window comprising 180 post-event trading days. The returns are presented as daily percentages along with the corresponding $t$-ratios. We present the raw returns and also the abnormal returns calculated using the single index model approach described above. We employ the EPRA Developed Market and S\&P500 indices as benchmarks in columns 4-5 and 6-7 respectively. The final column presents the number of firms in the sample, $N$, on each day during the event window. It is clear that the figure is near the maximum available of 366 for most days, although a handful 
are lost before the event - due, for example, to firms making their debut on the market and then being listed in an EPRA index the same day or a day or two later.

The most salient feature is one of positive and highly statistically significant positive returns until the day before index inclusion but then an almost zero return on the event day. We therefore conclude that market participants are aware that a company will enter the index and exert net buying pressure on the days before index entry. Focusing on the raw returns, these are positive on four of the five final pre-event trading days, and are largest (1.34\%) and most significant $(t$-ratio $=7.66$ ) on the day just before the stock enters the index, cumulating in an average pre-event week's return of $2.4 \%$. The event day return is not statistically significant but there is a larger (although still not significant) average return of $0.75 \%$ during the three trading weeks following index inclusion. Over the longer-run window, the average return is highly significant and positive at around $13 \%$.

It is clear that the use of abnormal or raw returns makes no qualitative difference to the results, but subtracting the market-required rates of return reduces both the short-run and long-run returns compared to their unadjusted values, perhaps indicating that index recompositions tend to occur around times of buoyancy in the overall market.

Table 2 presents a parallel set of results to Table 1, except that we now focus on deletions. It is evident from the final column that the sample is now much smaller, and this somewhat reduces the statistical significance of the results, although not their salience. Again, the conclusions are unaltered whether we examine raw or risk-adjusted returns. Returns are persistently negative for the whole pre-deletion trading week, although they are not significant except for the day before the event. Prices fall on average by $1.5 \%$ each day from $t-5$ to $t-2$, and then by almost $10 \%$ the day before the event. On the actual day that the firms are removed from their indices, there is a bounce-back, with prices rising on average by a statistically significant $8.6 \%$ and then by a further cumulative (statistically significant) $13 \%$ during the three trading weeks following deletion. Thus, examining the entire short-run event window from one week before to three weeks after the event, prices rise, rather than fall, by around 5-6\%, depending on whether raw or abnormal returns are considered. Examining the long-run post-event cumulative returns in the final row of Table 2, these are large, positive (of the order of 40\%), and statistically significant. 
At first blush, these results seem odd, with deletions having larger (i.e. more positive) effects than additions for the event day and the period following it. One possible explanation is that the additional media attention that arises from the news of a deletion, despite it representing bad news, puts the company on the radar of investors such that net buying pressure rises rather than falls. There is some evidence that this is indeed the case for stocks (see Barber and Odean, 2008).

Another possible explanation is that these results are being driven by the behaviour of a small number of specific firms during the event period. The number of additions is sufficiently large that we would expect the presence of outliers in the sample to have negligible effects on the overall patterns of returns. However, for the deletions sample, at 38, this argument does not apply. An examination of the data shows that indeed there are a number of instances where the prices of certain stocks rise and then fall again substantially the next day, particularly for the deletions sample. For instance, the price of UK firm Minerva fell $21 \%$ around 5 months prior its deletion from the Liquid 40 Index on 1 April 2001 and then fell a further 32\% the very next day. An even more extreme example is that of Quintain Estates and Development, again a UK based firm, that was deleted from the Liquid 40 Index on 21 June 2010. On 31 March 2009, it's price fell by $45 \%$ in a single day, but then rose by $69 \%, 46 \%, 25 \%, 13 \%$ and $22 \%$, an overall rise of $330 \%$ during the following five trading days.

Given the potential effect that these sorts of extreme price moments could have, we remove from the samples of additions and deletions any returns that are greater than $20 \%$ in absolute value. This threshold is, of course, entirely arbitrary, but should at least avoid the most egregious examples of anomalous behaviour that is almost certainly not due to the index effect in any case. Given that it is impossible to separate out the index recomposition effect from any other corporate events that may be taking place for a particular company, this is the only approach we can adopt. Note that the number of sample firms remains the same as above, but we remove individual return observations (i.e. they are set to missing values) that fall outside of these $\pm 20 \%$ bounds. We then repeat all of the analysis above and produce Tables 3 and 4 , which are identical to Tables 1 and 2 respectively but are constructed based on the samples with outlying returns removed. We also plot the cumulative average abnormal return performance (EPRA benchmark adjusted) for the average addition and deletion from day t-5 to day $\mathrm{t}+15$ (Figures 1 and 2 respectively). 
As we expected, not only because of the larger sample size, but also because of the much lower proportion of returns considered outliers, the results for additions are qualitatively identical to the full sample results presented in Table 1 and the average returns change only by a few basis points per day. Therefore, we need not discuss Table 3 further. For the deletions in Table 4, however, the story is very different. Focusing on the raw returns, it is clear that the outliers had a considerable impact on the results and presented a misleading picture. Once they are removed, the pre-event returns are still highly significant and negative: $-11.5 \%(t$-ratio $=-4.87)$ for the week before the deletion takes place. Although there is still a reversal on average both on day $t$ (a return of $1.5 \%$ with a $t$-ratio of 1.5 ) and cumulatively over the three post-deletion weeks (a return of $5.5 \%$ with a $t$-ratio of 1.3 ), it is evident that these figures are much smaller than before and are no longer statistically significant. We can therefore conclude that the reversal (i.e. the subsequent price rise) is only partial and over the whole event window the return is around $-5 \%$. Similarly, the long-run post-event performance is now a negative $-3.3 \%$, although it is not significant, where it was $+40 \%$ previously. Given that these outlier-removed results are comparable for additions but much more sensible for deletions, we proceed to employ these rather than the unadjusted data in all subsequent return-based analysis.

Studies involving the S\&P500 have argued that since the announcement regarding changes in the composition of the index are made when the market is closed, most of the announcement effect can never be realised by traders since the price trades at a higher (lower) level immediately at the open the day after the announcement for additions (deletions). It is thus argued in this literature that it is important to examine the open-to-close return on the event date rather than the typical daily returns which are usually measured on a close-to-close basis. However, for the sample of firms that we consider, it is clear from the returns that investors know about index recompositions and trade on this information at least a few days prior to them taking place. As such, there is only a minimal return on the event day and therefore no need to be concerned with this issue.

\section{2: Index Effects by Country}

In Tables 5 and 6, we examine the index effects for the abnormal returns using the EPRA benchmark and with outliers removed separately by country (or more accurately, by currency area). We separate the sample and analyse the UK, the euro-zone, Denmark, Norway, Sweden, Switzerland and the UK for additions, and the euro-zone and the UK for deletions (since there are insufficient data points for reliability regarding the other countries). 
Considering the additions in Table 5, the first point to note is that the results are qualitatively identical for all countries, although the magnitudes are quite different. The biggest effect is for Denmark, with a cumulative return of almost $6 \%$ the week before an addition including a return of nearly $4 \%$ on day $t-1$, and a further cumulative return of just under $4 \%$ the three weeks after the event. For all other countries in the additions sample, the short-run effects are relatively muted, although they are slightly stronger for the euro-zone and weakest in the UK and Switzerland. The long-run figures paint a different picture, however, with cumulative returns of $21 \%$ for Denmark and for Sweden, $10 \%$ for the UK, $6 \%$ for Switzerland, but less than $5 \%$ for Norway and the euro-zone.

Focusing now on the deletions sample in Table 6, the effects are similar for the UK and eurozone and the results confirm those of Table 4 above. There are highly significant negative returns during the week before the event (-9.5\% for the euro-zone and $-16.7 \%$ for the UK, with little price movement on day $t$ but further considerable (although not statistically significant) falls over the long run (-4.6\% for the euro-zone and $-10.7 \%$ for the UK).

\section{3: Index Effects for Small versus Large Firms}

It is possible that the event of an addition or deletion will have a bigger impact on smaller capitalisation stocks than on otherwise identical stocks that are larger. The argument would go that large cap stocks are already liquid, heavily traded, and widely tracked by analysts. Larger firms may already be included in institutional investors' portfolios and any information content of index membership may not play a significant role. Smaller firms, on the other hand, derive more relative advantage when being in the index, and one should therefore expect those firms to keep more of the positive return realised during the event period. Moreover, smaller firms may be subject to less frequent announcements and therefore, information effects may be more important (Ohlson, 1979). Finally, small firms are also more likely to be affected by the positive liquidity shock of inclusion. As such, small stocks arguably have more to gain from additions, and more to lose from deletions, than large stocks, in part since the impact of being included in an index on the profile of a small firm will be considerably greater, possibly propelling them into the media spotlight and creating important new demand for their shares from index trackers. 
To test this conjecture, we sort the pooled sample of additions (after the removal of outlying observations as discussed above) by market capitalisation into three portfolios (two portfolios for deletions) containing equal numbers of stocks - a portfolio of small stocks, a portfolio of medium-sized stocks, and a portfolio of the largest capitalisation stocks ${ }^{8}$. We then examine the cumulative abnormal returns relative to the benchmark over the key date ranges around index inclusion (in Table 7) and deletion (in Table 8). For the additions in Table 7, the results clearly support the suggestion, since there is a clear monotonic reduction in abnormal returns when moving from small through medium to large firms over all of the relevant date ranges, except on day $t$ where medium-sized firms have the largest reversal of the previous days' price increases. So the average cumulative abnormal returns over the pre-event week are around $1.4 \%$ (significant at the $1 \%$ level) for small firms but only $1.2 \%$ for larger firms (significant at the 5\% level). Over the long-run post-event window ( $t$ to $t+180)$, the results are even more striking - the return is almost $16 \%$ for the smallest tricile of firms (significant at the $0.1 \%$ level), $5 \%$ for medium sized firms (significant at the $10 \%$ level) but only $4 \%$ for the largest firms (not even significant at the $20 \%$ level). For the deletions in Table 6, the pre-event fall in price is considerably greater in both magnitude $(-18.6 \%$ versus $-7.2 \%)$ and statistical significance ( $t$-ratio of -6.1 versus -2.7) for the small firms than the large, and the post-event reversal over the following three trading weeks is more marked for the small firm sample $(10.2 \%$ versus $3.6 \%)$, and is marginally significant.

\section{4: Index Effects and Volatility}

Cooper and Woglom (2001) argue that the increase in trading that occurs around the time of an index addition will cause its volatility, a measure of its total risk, to rise. A combination of increased demand by index funds, and speculation by arbitrageurs and noise traders (see also De Long et al., 1990) can cause a temporary increase in volatility. However, provided that inclusion in the index, or removal from it, does not affect a firm's underlying operating performance and therefore its cashflows, there should be no long-run effect on volatility.

We examine in Table 9 whether the volatility of abnormal returns changes after index recompositions for additions and deletions. We again employ the sample where outlying observations have been deleted from the database. In order to minimise the noise that occurs around the event period itself, we focus on long-run volatility and measure the standard deviation of returns from 250 days before the event to 250 days after. When we compare the actual levels of volatility before and after the event, we find that both fall modestly - by $1.2 \%$ 
for additions and by $6.1 \%$ for deletions. If we compute the ratio of variances of the pre- over post-event periods, this constitutes a test statistic to examine the null hypothesis that the variances are equal. Considering the $p$-values for these tests in the final row of Table 9, it is evident that there is no significant change in volatility following index inclusion or removal. This lends support to the notion that index changes do not have discernible impacts on the underlying performance of the firm over the long run ${ }^{9}$.

\section{5: The Impact on Trading Activity}

Table 10 reports the volume ratios around the time of the event for the additions and deletions samples constructed using the methods described above. We also present the $t$-ratios that test the null hypothesis that the true volume ratio is unity on each day. Considering first the additions sample, we can see that the ratios are highest on days $t-2(4.6)$ and $t+1(2.1)^{10}$. The former is a remarkably high figure, with the value of shares traded per day being on average almost five times its usual value, although interestingly it is not statistically significantly different from one, indicating a considerable amount of variation across companies within the sample. For deletions, the volume ratios are highest on day $t-1$ (2.8), $t(2.2), t+1$ (3.3) and $t+4$ (2.4). Taken together, these figures clearly indicate that there is enhanced trading activity both before and after the event ${ }^{11}$. In order to ascertain whether this continues in the longer run after the initial impact of index addition or deletion subsides, the second panel of Table 8 shows the average (over firms and across the days within the window) volume ratios. Indeed it is the case that volume ratios are highest around the event (just before day $t$ for additions but on day $t$ for deletions), and the volumes never fall back to their pre-event values, even several months afterward. This is consistent with the broad finance literature. It is a common occurrence that trading volumes increase due to market maturity and/or increased investor awareness. Specifically these are findings broadly supportive of the liquidity hypothesis ${ }^{12}$.

In order to ascertain whether the largest price movements take place at the same times that trading activity peaks, Figures 3 and 4 present volume ratios (left-hand scale shown using bars) and returns (right-hand scale shown using a line) in the same graph for additions and deletions respectively. From Figure 3 for additions, it is hard to identify much similarity between the patterns of trading activity, which peaks on day $t$-2 but remains above its long-term average value throughout the event window, and returns, which are mostly positive throughout but peak on day $t$-1. Similarly for the deletions in Figure 4, large volumes and large price movements are not coincidental. Returns are persistently below zero before the event but slightly positive 
on day $\mathrm{t}$ and thereafter, while volumes peak on day $t+1$ (also when the largest negative return of over $5 \%$ occurs), but are also particularly high on day $t+1, t+4$ and $t+6$ whereas returns on those days are all very close to zero. Finally, Figure 5 plots the volume ratios for additions and deletions side-by-side to make it easy to determine whether their peaks coincide or not. It is clear from the figure that they do only to a limited extent - both are around the event date, with volumes for additions peaking on day $t-2$ and those for deletions being higher than their usual figures on days $t-1$ to $t+1$.

\section{6: The Incorporation of Earnings per Share}

In order to determine whether the long-term operating performance of the firms is affected by index inclusion or removal, we now investigate whether the earnings per share (EPS) of the securities change after the event. Previous studies have also employed the price-earnings (P/E) ratio for this purpose - see, for example, Malkiel and Radisich (2001); however, such ratios are driven not only by operating performance as captured by the earnings, but also the share price itself and as such, any changes picked up by the analysis may simply be capturing the price effects that we have already discussed. EPS calculations also bring with them another issue however, which is that while P/E ratios are unit free, EPS have the units of the currency of denomination of their stock; this is not a problem for studies focused on a single country, but is in our instance since we have a pan-European sample. In order to conduct a valid analysis, we therefore separate the whole sample into separate country sub-samples where the number of firms is sufficiently large: the UK, the Euro-zone, Sweden, Denmark, Norway and Switzerland for additions, and the UK, the Eurozone and Sweden for deletions.

It has been argued that index inclusion may afford added firms better relationships with financial institutions concerning their debts or other liabilities (Chen et al., 2002), thus specifically implying that index membership causes better operating performance through lowering the costs of debt. Alternatively, it has been argued that a strong and growing earnings profile is correlated with index inclusion and a weak and deteriorating profile with removal, and thus the index recomposition is the effect of the operating performance and not the cause.

We compare the figures one year before the event and one year after, and the results are presented in Table 11 for additions and Table 12 for deletions. For four of the six countries analysed, earnings increase by around $20-40 \%$ the year after inclusion (Table 11), although for Norway and Switzerland (the two smallest countries that we analyse in terms of numbers of 
additions), they fall by around 20\%. A $t$-test for the equality of the mean EPS figure before and after the event shows no significant values for any of the six countries, however. Interestingly, earnings also rise after deletion events, as shown by Table 12 - by around $20 \%$ in the UK and Swedish cases but only by $1 \%$ in the Euro-zone. The results with respect to operational performance, as measured by EPS, do have to be placed into context when considering real estate firms. The nature of the cash flows that real estate companies derive generally displays far greater stability than in many other industries. Therefore, it is not surprising that our findings do not display the same magnitude of changes as observed in some of the mainstream finance literature.

\section{5: Concluding Comments}

This paper has added to the literature examining the impact of firms entering and leaving benchmark indices. Where this paper differs from extant studies is through the consideration of multiple indices, in this case the FTSE EPRA NAREIT family of indices. Our study constitutes one of only a handful to examine sector-specific indices rather than those that are market-wide. We examine the effect on prices, trading volumes, volatilities and operating performance in the short- and longer-terms. Our key finding is that the prices of newly included companies rise, and those of deleted firms fall, around the time of the index changes. We also conclude that index inclusion has a long-lasting, even permanent, effect upon trading volumes. However, there is also evidence of arbitrage activity and/or tracker fund purchases of additions and sales of deletions around the time of index re-compositions. There is no evidence, however, that index changes significantly affect volatility of price changes or firm operating performance as measured by their earnings per share.

Returning to the hypotheses that we outlined at the beginning of the paper, we could argue that since the price increases for additions and the falls that occur for deletions appear to be largely permanent and are not subsequently reversed, this finding lends weight to the information content hypothesis. That the price changes around index re-compositions are not temporary effectively rules out the price pressure hypothesis. The results on volumes, where they rise substantially around the time of the event but never subsequently return to their pre-event values is also supportive of the liquidity hypothesis where index membership increases liquidity through enhanced trading activity that arises as a result of heightened investor awareness of specific firms that enter the media spotlight following the announcement of either an addition or a deletion. 


\section{References:}

Akimov, A., Hutson, E. and Stevenson, S. (2012). The Interaction of Volatility, Volume and Skewness: Empirical Evidence from REITs, working paper, University of Reading.

Ambrose, B.W., Lee, D.W. and Peek, J. (2006).Comovement after Joining an Index: Spillovers of Non-fundamental Effects, Real Estate Economics, 35, 57-90.

Beneish, M. and Whaley, R. (1996). An Anatomy of the "S\&P Game": The Effects of Changing the Rules, Journal of Finance, 51, 1909-1930.

Barber, T.M., and Odean, T. (2008). All that Glitters: The Effect of Attention and News on the Buying Behavior of Individuals and Institutional Investors, Review of Financial Studies, 21, 785-818.

Chen, H., Noronha, G. and Singal, V. (2002). Investor Recognition and Market Segmentation: Evidence from S\&P 500 Index Changes, working paper.

Chen, H., Noronha, G. and Singal, V. (2004). The Price Response to the S\&P 500 Additions and Deletions: Evidence of Asymmetry and a New Explanation, Journal of Finance, 59, 19011929.

Cooper, D. and Woglom, G. (2001). The S\&P 500 Effect: Not Such Good News in the Long Run, FEDS Working Paper No 2002-48.

Cotter, J. and Stevenson, S. (2008). Modelling Long Memory in REITs, Real Estate Economics, 36, 533-554.

De Long, B., Shleifer, A., Summers, L. and Waldman, R. (1990). Noise Trader Risk in Financial Markets. Journal of Political Economy, 98, 703-38

Dhillon, U. and Johnson, H. (1991).Changes in the Standard and Poor's 500 List, Journal of Business, 64, 75-85.

Edmister, R., Graham, S. and Pirie, W. (1996). Trading Cost Expectations: Evidence from S\&P 500 Index Replacement Stock Announcements, Journal of Economics and Finance, 20, 75-85.

Erwin, G. and Miller, J. (1998). The Liquidity Effects Associated with Addition of a Stock to the S\&P 500 Index: Evidence from Bid/Ask Spreads, The Financial Review, 33, 131-146.

Feng, Z., Ghosh, C. and Sirmans, C.F. (2006). Changes in REIT Stock Prices, Trading Volume and Institutional Ownership Resulting from S\&P REIT Index Changes, Journal of Real Estate Portfolio Management, 12, 59-71.

Goodacre, A. and Lawrence, M. (1994). Price and Volume Effects Associated with Changes in the Constituents of the FTSE 100 Index, Working paper, University of Stirling.

Harris, L. and Gurel, E. (1986). Price and Volume Effects Associated with Changes in the S\&P 500 List: New Evidence for the Existence of Price Pressures, Journal of Finance, 41, 815-829. 
Hung, S.Y.K. and Glascock, J. (2010). Volatilities and Momentum Returns in Real Estate Investment Trusts, Journal of Real Estate Finance and Economics, 41, 126-149.

Jain, P. (1987). The Effect on Stock Price of Inclusion or Exclusion from the S\&P 500, Financial Analysts Journal, 43, 58-65.

Kappou, K., Brooks, C. and Ward, C. (2008). A re-examination of the Index Effect: Gambling on Additions to and Deletions from the S\&P 500's Gold Seal, Research in International Business and Finance, 22, 325-350.

Kappou, K., Brooks, C. and Ward, C. (2010). The S\&P 500 Index Effect Reconsidered: Evidence from Overnight and Intraday Stock Price Performance and Volume, Journal of Banking and Finance, 34, 116-126.

Lamoureux, C. and Wansley, J. (1987).Market Effects of Changes in the Standard and Poor's 500 Index, The Financial Review, 22, 53- 69.

Lee C.L., Stevenson, S. and Lee, M.L. (2012). Futures Trading, Spot Price Volatility and Market Efficiency: Evidence from European Real Estate Securities Futures, working paper, University of Reading.

Lynch, A. and Mendenhall, R. (1997). New Evidence on Stock Price Effects Associated with Changes in the S\&P 500 Index, Journal of Business, 70, 351-383.

Malkiel, B. and Radisich, A. (2001). The Growth of Index Funds and the Pricing of Equity Securities, Journal of Portfolio Management, 27, 9-21.

Mikkelson, H. and Partch, M. (1985). Stock Price Effects and Costs of Secondary Distributions, Journal of Financial Economics, 14, 165-194.

Morck, R. and Yang, F. (2002).The Mysterious Growing Value of S\&P 500 Membership, NBER Working Paper, No. w8654.

Ohlson, J. (1979). On Financial Disclosures and the Behavior of Security Prices, Journal of Accounting and Economics, 1, 211-232.

Shleifer, A. (1986). Do Demand Curves for Stocks Slope Down? Journal of Finance, 41, 579590.

Woolridge, R. and Ghosh, C. (1986). Institutional Trading and Security Prices: The Case of Changes in the Composition of the S\&P 500 Index, Journal of Financial Research, 9, 13-24.

Wurgler, J. and Zhuravskaya, E. (2002). Does Arbitrage Flatten Demand Curves for Stocks? Journal of Business, 75, 583-608. 
Table 1: Returns for the Pooled Sample of Additions

\begin{tabular}{|c|c|c|c|c|c|c|c|}
\hline \multirow[t]{2}{*}{ Day } & \multicolumn{2}{|c|}{ Raw Returns } & \multicolumn{2}{|c|}{$\begin{array}{l}\text { Abnormal Returns } \\
\text { (EPRA Benchmark) }\end{array}$} & \multicolumn{2}{|c|}{$\begin{array}{l}\text { Abnormal Returns } \\
\text { (S\&P Benchmark) }\end{array}$} & \multirow[t]{2}{*}{$N$} \\
\hline & Return (\%) & t-ratio & Return (\%) & t-ratio & Return (\%) & t-ratio & \\
\hline$t-5$ & 0.50 & 2.86 & 0.35 & 2.25 & 0.39 & 2.34 & 358 \\
\hline $\mathrm{t}-4$ & -0.43 & -2.47 & -0.03 & -0.22 & -0.05 & -0.32 & 358 \\
\hline$t-3$ & 0.49 & 2.79 & 0.20 & 1.29 & 0.33 & 1.99 & 359 \\
\hline$t-2$ & 0.50 & 2.86 & 0.14 & 0.91 & 0.23 & 1.38 & 360 \\
\hline $\mathrm{t}-1$ & 1.34 & 7.66 & 0.68 & 4.35 & 0.79 & 4.70 & 364 \\
\hline $\mathrm{t}$ & 0.05 & 0.31 & -0.01 & -0.08 & 0.02 & 0.12 & 366 \\
\hline$t+1$ & 0.20 & 1.15 & -0.05 & -0.34 & 0.04 & 0.21 & 366 \\
\hline$t+2$ & -0.29 & -1.66 & -0.09 & -0.59 & -0.20 & -1.21 & 366 \\
\hline$t+3$ & -0.15 & -0.84 & 0.12 & 0.76 & 0.09 & 0.54 & 366 \\
\hline $\mathrm{t}+4$ & 0.35 & 2.02 & 0.33 & 2.13 & 0.34 & 2.02 & 366 \\
\hline $\mathrm{t}+5$ & -0.07 & -0.41 & 0.02 & 0.13 & -0.02 & -0.14 & 366 \\
\hline$t+6$ & 0.24 & 1.36 & 0.10 & 0.64 & 0.17 & 0.99 & 366 \\
\hline $\mathrm{t}+7$ & -0.02 & -0.10 & -0.02 & -0.15 & -0.04 & -0.26 & 366 \\
\hline$t+8$ & 0.43 & 2.44 & 0.30 & 1.91 & 0.40 & 2.39 & 366 \\
\hline $\mathrm{t}+9$ & 0.29 & 1.66 & 0.19 & 1.22 & 0.10 & 0.61 & 366 \\
\hline$t+10$ & -0.08 & -0.44 & -0.04 & -0.25 & 0.08 & 0.46 & 366 \\
\hline$t+11$ & 0.04 & 0.21 & -0.06 & -0.36 & -0.07 & -0.43 & 365 \\
\hline$t+12$ & -0.04 & -0.22 & -0.06 & -0.42 & 0.01 & 0.08 & 365 \\
\hline$t+13$ & 0.01 & 0.04 & 0.12 & 0.79 & 0.03 & 0.17 & 365 \\
\hline$t+14$ & 0.01 & 0.06 & -0.12 & -0.78 & -0.13 & -0.78 & 364 \\
\hline$t+15$ & -0.17 & -0.96 & -0.20 & -1.26 & -0.21 & -1.24 & 364 \\
\hline \multicolumn{8}{|c|}{$\underline{\text { Cumulative Returns }}$} \\
\hline $\mathrm{t}-5$ to $\mathrm{t}-1$ & 2.40 & 6.13 & 1.33 & 3.83 & 1.70 & 4.51 & \\
\hline t only & 0.05 & 0.31 & -0.01 & -0.08 & 0.02 & 0.12 & \\
\hline$t+1$ to $t+15$ & 0.75 & 1.11 & 0.54 & 0.89 & 0.57 & 0.88 & \\
\hline $\mathrm{t}$ to $\mathrm{t}+180$ & 13.05 & 5.54 & 9.61 & 4.59 & 12.61 & 5.58 & \\
\hline
\end{tabular}


Table 2: Returns for the Pooled Sample of Deletions

\begin{tabular}{|c|c|c|c|c|c|c|c|}
\hline \multirow[t]{2}{*}{ Day } & \multicolumn{2}{|c|}{ Raw Returns } & \multicolumn{2}{|c|}{$\begin{array}{l}\text { Abnormal Returns } \\
\text { (EPRA Benchmark) }\end{array}$} & \multicolumn{2}{|c|}{$\begin{array}{l}\text { Abnormal Returns } \\
\text { (S\&P Benchmark) }\end{array}$} & \multirow[t]{2}{*}{$N$} \\
\hline & Return (\%) & t-ratio & Return (\%) & t-ratio & Return (\%) & t-ratio & \\
\hline$t-5$ & -1.83 & -1.40 & -1.52 & -1.22 & -1.77 & -1.38 & 38 \\
\hline $\mathrm{t}-4$ & -1.13 & -0.87 & -2.04 & -1.64 & -2.12 & -1.66 & 38 \\
\hline $\mathrm{t}-3$ & -1.42 & -1.09 & -1.70 & -1.36 & -1.40 & -1.09 & 38 \\
\hline $\mathrm{t}-2$ & -1.73 & -1.33 & -1.39 & -1.12 & -1.72 & -1.34 & 38 \\
\hline $\mathrm{t}-1$ & -9.05 & -6.95 & -9.71 & -7.79 & -9.60 & -7.49 & 38 \\
\hline $\mathrm{t}$ & 8.61 & 6.62 & 8.77 & 7.04 & 8.81 & 6.87 & 38 \\
\hline$t+1$ & 1.59 & 1.22 & 1.19 & 0.95 & 1.27 & 0.99 & 38 \\
\hline$t+2$ & 1.67 & 1.28 & 2.11 & 1.69 & 1.82 & 1.42 & 38 \\
\hline$t+3$ & -0.36 & -0.28 & -0.24 & -0.19 & -0.30 & -0.23 & 38 \\
\hline $\mathrm{t}+4$ & -0.34 & -0.26 & -0.34 & -0.27 & -0.07 & -0.06 & 38 \\
\hline$t+5$ & -0.52 & -0.40 & -0.09 & -0.07 & -0.59 & -0.46 & 38 \\
\hline$t+6$ & 1.45 & 1.11 & 1.00 & 0.80 & 1.08 & 0.84 & 37 \\
\hline $\mathrm{t}+7$ & -0.50 & -0.39 & -0.80 & -0.64 & -0.63 & -0.49 & 37 \\
\hline$t+8$ & 2.21 & 1.70 & 2.29 & 1.84 & 2.57 & 2.00 & 37 \\
\hline $\mathrm{t}+9$ & 2.22 & 1.71 & 2.40 & 1.92 & 2.08 & 1.62 & 37 \\
\hline$t+10$ & 3.08 & 2.37 & 3.55 & 2.85 & 3.76 & 2.93 & 37 \\
\hline$t+11$ & 1.01 & 0.77 & 0.54 & 0.43 & 0.77 & 0.60 & 37 \\
\hline $\mathrm{t}+12$ & 0.03 & 0.02 & 0.06 & 0.05 & 0.32 & 0.25 & 37 \\
\hline$t+13$ & 1.23 & 0.95 & 0.79 & 0.64 & 0.97 & 0.75 & 37 \\
\hline$t+14$ & -0.91 & -0.70 & -1.05 & -0.84 & -0.73 & -0.57 & 37 \\
\hline $\mathrm{t}+15$ & 1.15 & 0.89 & 1.48 & 1.19 & 1.31 & 1.02 & 37 \\
\hline \multicolumn{8}{|c|}{ Cumulative Returns } \\
\hline $\mathrm{t}-5$ to $\mathrm{t}-1$ & -15.15 & -5.21 & -16.36 & -5.87 & -16.61 & -5.80 & \\
\hline t only & 8.61 & 6.62 & 8.77 & 7.04 & 8.81 & 6.87 & \\
\hline$t+1$ to $t+15$ & 13.02 & 2.58 & 12.88 & 2.67 & 13.62 & 2.74 & \\
\hline $\mathrm{t}$ to $\mathrm{t}+180$ & 40.03 & 2.29 & 41.00 & 2.44 & 45.22 & 2.62 & \\
\hline
\end{tabular}


Table 3: Returns for the Pooled Sample of Additions with Outliers Removed

\begin{tabular}{|c|c|c|c|c|c|c|c|}
\hline & \multicolumn{2}{|c|}{ Raw Returns } & \multicolumn{2}{|c|}{$\begin{array}{l}\text { Abnormal Returns } \\
\text { (EPRA Benchmark) }\end{array}$} & \multicolumn{2}{|c|}{$\begin{array}{l}\text { Abnormal Returns } \\
\text { (S\&P Benchmark) }\end{array}$} & \multirow[t]{2}{*}{$N$} \\
\hline & Return (\%) & t-ratio & Return (\%) & t-ratio & Return (\%) & t-ratio & \\
\hline \multicolumn{8}{|l|}{ Day } \\
\hline $\mathrm{t}-5$ & 0.50 & 3.01 & 0.36 & 2.36 & 0.40 & 2.47 & 358 \\
\hline $\mathrm{t}-4$ & -0.43 & -2.60 & -0.03 & -0.23 & -0.06 & -0.35 & 358 \\
\hline $\mathrm{t}-3$ & 0.49 & 2.93 & 0.20 & 1.32 & 0.33 & 2.07 & 359 \\
\hline $\mathrm{t}-2$ & 0.50 & 3.01 & 0.15 & 0.96 & 0.24 & 1.45 & 360 \\
\hline $\mathrm{t}-1$ & 1.22 & 7.25 & 0.62 & 4.14 & 0.73 & 4.52 & 364 \\
\hline $\mathrm{t}$ & 0.06 & 0.33 & -0.09 & -0.59 & -0.06 & -0.35 & 366 \\
\hline $\mathrm{t}+1$ & 0.20 & 1.21 & -0.05 & -0.33 & 0.04 & 0.24 & 366 \\
\hline$t+2$ & -0.29 & -1.75 & -0.10 & -0.63 & -0.20 & -1.26 & 366 \\
\hline$t+3$ & -0.15 & -0.88 & 0.12 & 0.79 & 0.09 & 0.56 & 366 \\
\hline$t+4$ & 0.35 & 2.12 & 0.34 & 2.23 & 0.34 & 2.11 & 366 \\
\hline$t+5$ & -0.07 & -0.43 & 0.02 & 0.14 & -0.02 & -0.15 & 366 \\
\hline$t+6$ & 0.24 & 1.43 & 0.11 & 0.71 & 0.17 & 1.04 & 366 \\
\hline$t+7$ & -0.02 & -0.10 & -0.03 & -0.17 & -0.04 & -0.28 & 366 \\
\hline$t+8$ & 0.43 & 2.56 & 0.30 & 1.98 & 0.40 & 2.47 & 366 \\
\hline $\mathrm{t}+9$ & 0.29 & 1.74 & 0.19 & 1.24 & 0.10 & 0.63 & 366 \\
\hline$t+10$ & -0.08 & -0.46 & -0.04 & -0.27 & 0.07 & 0.46 & 366 \\
\hline$t+11$ & 0.04 & 0.22 & -0.06 & -0.37 & -0.07 & -0.44 & 365 \\
\hline$t+12$ & -0.04 & -0.23 & -0.07 & -0.46 & 0.01 & 0.06 & 365 \\
\hline$t+13$ & 0.01 & 0.04 & 0.12 & 0.79 & 0.03 & 0.17 & 365 \\
\hline$t+14$ & 0.01 & 0.06 & -0.12 & -0.80 & -0.13 & -0.81 & 364 \\
\hline$t+15$ & -0.17 & -1.01 & -0.19 & -1.28 & -0.21 & -1.28 & 364 \\
\hline \multicolumn{8}{|c|}{ Cumulative Returns } \\
\hline $\mathrm{t}-5$ to $\mathrm{t}-1$ & 2.28 & 6.09 & 1.29 & 3.83 & 1.64 & 4.55 & \\
\hline t only & 0.06 & 0.33 & -0.09 & -0.59 & -0.06 & -0.35 & \\
\hline $\mathrm{t}+1$ to $\mathrm{t}+15$ & 0.76 & 1.17 & 0.54 & 0.92 & 0.57 & 0.91 & \\
\hline $\mathrm{t}$ to $\mathrm{t}+180$ & 11.56 & 5.13 & 8.15 & 4.02 & 11.08 & 5.09 & \\
\hline
\end{tabular}


Table 4: Returns for the Pooled Sample of Deletions with Outliers Removed

\begin{tabular}{|c|c|c|c|c|c|c|c|}
\hline \multirow[t]{2}{*}{ Day } & \multicolumn{2}{|c|}{ Raw Returns } & \multicolumn{2}{|c|}{$\begin{array}{l}\text { Abnormal Returns } \\
\text { (EPRA Benchmark) }\end{array}$} & \multicolumn{2}{|c|}{$\begin{array}{l}\text { Abnormal Returns } \\
\text { (S\&P Benchmark) }\end{array}$} & \multirow[t]{2}{*}{$N$} \\
\hline & Return (\%) & t-ratio & Return (\%) & t-ratio & Return (\%) & t-ratio & \\
\hline$t-5$ & -1.83 & -1.72 & -1.67 & -1.67 & 0.14 & 0.14 & 38 \\
\hline $\mathrm{t}-4$ & -2.02 & -1.90 & -2.59 & -2.59 & -0.22 & -0.22 & 38 \\
\hline$t-3$ & -1.42 & -1.34 & -1.72 & -1.72 & 2.01 & 2.01 & 38 \\
\hline$t-2$ & -1.06 & -0.99 & -1.00 & -1.01 & 0.45 & 0.45 & 38 \\
\hline $\mathrm{t}-1$ & -5.23 & -4.93 & -5.43 & -5.44 & -0.98 & -0.98 & 38 \\
\hline $\mathrm{t}$ & 1.55 & 1.46 & 1.23 & 1.23 & -1.66 & -1.66 & 38 \\
\hline$t+1$ & 1.05 & 0.99 & 0.52 & 0.52 & -2.58 & -2.58 & 38 \\
\hline$t+2$ & 0.57 & 0.54 & 0.94 & 0.94 & -1.71 & -1.71 & 38 \\
\hline$t+3$ & -0.36 & -0.34 & -0.19 & -0.19 & -1.00 & -1.00 & 38 \\
\hline $\mathrm{t}+4$ & -0.34 & -0.32 & -0.30 & -0.30 & -5.43 & -5.43 & 38 \\
\hline$t+5$ & -0.52 & -0.49 & -0.46 & -0.46 & 1.23 & 1.24 & 38 \\
\hline$t+6$ & 0.42 & 0.40 & 0.07 & 0.07 & 0.53 & 0.53 & 37 \\
\hline$t+7$ & -0.50 & -0.47 & -0.53 & -0.53 & 0.94 & 0.95 & 37 \\
\hline$t+8$ & 1.01 & 0.95 & 1.28 & 1.28 & -0.17 & -0.17 & 37 \\
\hline $\mathrm{t}+9$ & 0.00 & 0.00 & 0.15 & 0.15 & -0.26 & -0.26 & 37 \\
\hline$t+10$ & 1.58 & 1.48 & 2.09 & 2.09 & -0.44 & -0.44 & 37 \\
\hline$t+11$ & 0.32 & 0.30 & -0.09 & -0.09 & 0.08 & 0.08 & 37 \\
\hline$t+12$ & 0.03 & 0.03 & -0.11 & -0.11 & -0.51 & -0.52 & 37 \\
\hline$t+13$ & 0.69 & 0.65 & 0.33 & 0.33 & 1.29 & 1.29 & 37 \\
\hline$t+14$ & 0.39 & 0.37 & 0.33 & 0.33 & 0.15 & 0.16 & 37 \\
\hline$t+15$ & 1.15 & 1.09 & 1.30 & 1.30 & 2.10 & 2.10 & 37 \\
\hline \multicolumn{8}{|c|}{ Cumulative Returns } \\
\hline $\mathrm{t}-5$ to $\mathrm{t}-1$ & -11.55 & -4.87 & -12.41 & -5.56 & -12.37 & -5.54 & \\
\hline t only & 1.55 & 1.46 & 1.23 & 1.23 & 1.23 & 1.24 & \\
\hline$t+1$ to $t+15$ & 5.49 & 1.34 & 5.34 & 1.38 & 5.48 & 1.42 & \\
\hline $\mathrm{t}$ to $\mathrm{t}+180$ & -3.35 & -0.23 & -4.10 & -0.30 & -2.83 & -0.21 & \\
\hline
\end{tabular}


Table 5: Returns for the Sample of Additions by Country with Outliers Removed

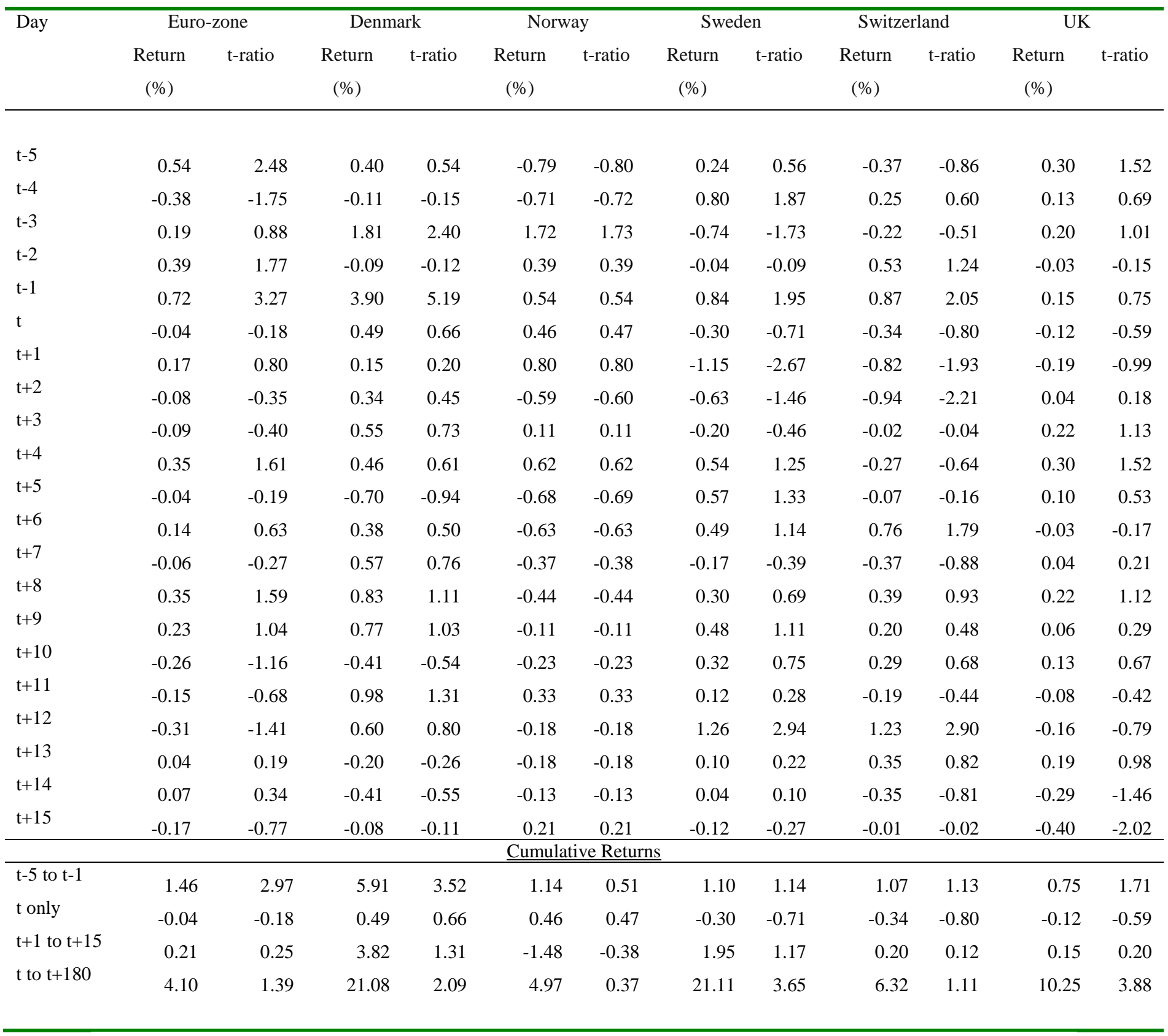


Table 6: Returns for the Sample of Deletions by Country with Outliers Removed

\begin{tabular}{|c|c|c|c|c|}
\hline \multirow[t]{2}{*}{ Day } & \multicolumn{2}{|c|}{ Euro-zone } & \multicolumn{2}{|c|}{ UK } \\
\hline & Return (\%) & t-ratio & Return (\%) & t-ratio \\
\hline$t-5$ & -1.01 & -0.87 & -2.52 & -1.86 \\
\hline $\mathrm{t}-4$ & -2.79 & -2.40 & -2.92 & -2.16 \\
\hline$t-3$ & -1.95 & -1.67 & -1.43 & -1.06 \\
\hline$t-2$ & 0.34 & 0.29 & -2.73 & -2.01 \\
\hline $\mathrm{t}-1$ & -4.09 & -3.51 & -7.09 & -5.23 \\
\hline $\mathrm{t}$ & 1.22 & 1.04 & 0.26 & 0.19 \\
\hline$t+1$ & 0.43 & 0.37 & 0.60 & 0.44 \\
\hline$t+2$ & 0.95 & 0.82 & 1.15 & 0.85 \\
\hline$t+3$ & 0.23 & 0.20 & -0.61 & -0.45 \\
\hline $\mathrm{t}+4$ & -1.26 & -1.08 & 0.67 & 0.50 \\
\hline$t+5$ & -1.68 & -1.45 & 0.78 & 0.58 \\
\hline$t+6$ & -0.91 & -0.78 & 1.32 & 0.97 \\
\hline $\mathrm{t}+7$ & -0.13 & -0.12 & -0.72 & -0.54 \\
\hline$t+8$ & 1.31 & 1.12 & 1.09 & 0.80 \\
\hline $\mathrm{t}+9$ & 0.49 & 0.42 & -0.38 & -0.28 \\
\hline$t+10$ & 1.70 & 1.46 & 1.69 & 1.25 \\
\hline$t+11$ & -1.20 & -1.03 & 0.89 & 0.65 \\
\hline$t+12$ & 0.24 & 0.21 & -0.85 & -0.63 \\
\hline$t+13$ & 0.34 & 0.29 & 0.69 & 0.51 \\
\hline$t+14$ & 0.33 & 0.28 & 0.32 & 0.24 \\
\hline$t+15$ & 2.14 & 1.84 & -0.02 & -0.01 \\
\hline \multicolumn{5}{|c|}{ Cumulative Returns } \\
\hline$t-5$ to $t-1$ & -9.49 & -3.64 & -16.68 & -5.51 \\
\hline t only & 1.22 & 1.04 & 0.26 & 0.19 \\
\hline$t+1$ to $t+15$ & 2.99 & 0.66 & 6.60 & 1.26 \\
\hline $\mathrm{t}$ to $\mathrm{t}+180$ & -4.63 & -0.30 & -10.74 & -0.59 \\
\hline
\end{tabular}


Table 7: Cumulative Returns for the Pooled Sample of Additions, Split by Firm Size, with Outliers Removed

\begin{tabular}{lrrrrrr}
\hline Day & \multicolumn{2}{c}{ Small Firms } & \multicolumn{2}{c}{ Medium Sized Firms } & \multicolumn{2}{c}{ Large Firms } \\
& Return (\%) & t-ratio & Return (\%) & t-ratio & Return (\%) & t-ratio \\
\hline $\mathrm{t}-5$ to $\mathrm{t}-1$ & 1.37 & 3.12 & 1.31 & 3.05 & 1.20 & 2.07 \\
$\mathrm{t}$ only & -0.02 & -0.08 & -0.21 & -1.09 & -0.04 & -0.16 \\
$\mathrm{t}+1$ to $\mathrm{t}+15$ & 2.36 & 3.11 & 0.40 & 0.54 & -1.36 & -1.36 \\
$\mathrm{t}$ to $\mathrm{t}+180$ & 15.86 & 6.03 & 4.62 & 1.80 & 4.15 & 1.20 \\
\hline
\end{tabular}

Table 8: Cumulative Returns for the Pooled Sample of Deletions, Split by Firm Size, with Outliers Removed

\begin{tabular}{lrrrr}
\hline Day & \multicolumn{3}{c}{ Small Firms } & \multicolumn{2}{c}{ Large Firms } \\
& Return (\%) & t-ratio & Return $(\%)$ & t-ratio \\
\hline t-5 to t-1 & -18.61 & -6.10 & -7.17 & -2.66 \\
$\mathrm{t}$ only & 2.19 & 1.60 & 0.43 & 0.36 \\
$\mathrm{t}+1$ to $\mathrm{t}+15$ & 10.16 & 1.92 & 3.61 & 0.77 \\
$\mathrm{t}$ to $\mathrm{t}+180$ & 2.41 & 0.13 & -8.89 & -0.55 \\
\hline
\end{tabular}

Table 9: Pre- and Post-Event Absolute and Relative Volatility

\begin{tabular}{|c|c|c|c|c|}
\hline & \multicolumn{2}{|c|}{ Additions $(\mathrm{N}=358)$} & \multicolumn{2}{|c|}{ Deletions $(\mathrm{N}=35)$} \\
\hline & Pre & Post & Pre & Post \\
\hline Average daily volatility & 1.73 & 1.71 & 4.12 & 3.87 \\
\hline \multicolumn{5}{|l|}{ Standard Deviation (\%) } \\
\hline $\begin{array}{c}\text { Percentage fall in volatility } \\
\text { after event }(\%)\end{array}$ & \multicolumn{2}{|c|}{1.16} & \multicolumn{2}{|c|}{6.07} \\
\hline Ratio of Variances (Post / Pre) & \multicolumn{2}{|c|}{1.01} & \multicolumn{2}{|c|}{1.14} \\
\hline $\begin{array}{c}\mathrm{p} \text {-value }\left(\mathrm{H}_{0} \text { : constant }\right. \\
\text { variance })\end{array}$ & \multicolumn{2}{|c|}{0.46} & \multicolumn{2}{|c|}{0.35} \\
\hline
\end{tabular}


Table 10: Volume Ratios on days t-5 to $\mathbf{t}+\mathbf{1 5}$ for Additions and Deletions

\begin{tabular}{|c|c|c|c|c|}
\hline \multirow[t]{2}{*}{ Day } & \multicolumn{2}{|c|}{ Additions } & \multicolumn{2}{|c|}{ Deletions } \\
\hline & Ratio & t-statistic & Ratio & t-statistic \\
\hline$t-5$ & 0.73 & -1.71 & 1.46 & 1.44 \\
\hline $\mathrm{t}-4$ & 1.24 & 0.96 & 1.21 & 0.88 \\
\hline$t-3$ & 0.97 & -0.22 & 1.42 & 1.20 \\
\hline $\mathrm{t}-2$ & 4.59 & 1.02 & 1.39 & 1.31 \\
\hline $\mathrm{t}-1$ & 1.80 & 2.61 & 2.82 & 3.11 \\
\hline $\mathrm{t}$ & 1.31 & 0.60 & 2.20 & 2.52 \\
\hline$t+1$ & 2.11 & 1.05 & 3.29 & 1.34 \\
\hline$t+2$ & 1.39 & 0.91 & 1.47 & 1.35 \\
\hline$t+3$ & 1.33 & 0.82 & 1.19 & 0.81 \\
\hline$t+4$ & 1.93 & 1.61 & 2.45 & 1.71 \\
\hline$t+5$ & 1.83 & 1.18 & 1.04 & 0.20 \\
\hline$t+6$ & 1.30 & 0.71 & 2.44 & 1.75 \\
\hline $\mathrm{t}+7$ & 1.98 & 1.56 & 1.55 & 1.74 \\
\hline $\mathrm{t}+8$ & 1.73 & 1.57 & 0.99 & -0.06 \\
\hline $\mathrm{t}+9$ & 1.75 & 1.56 & 1.44 & 1.26 \\
\hline$t+10$ & 1.68 & 1.03 & 1.34 & 1.00 \\
\hline$t+11$ & 2.04 & 0.78 & 0.96 & -0.25 \\
\hline$t+12$ & 1.34 & 1.21 & 1.19 & 1.10 \\
\hline$t+13$ & 1.52 & 1.33 & 1.22 & 0.49 \\
\hline$t+14$ & 1.04 & 0.27 & 1.25 & 0.77 \\
\hline$t+15$ & 2.70 & 1.13 & 1.19 & 0.94 \\
\hline \multicolumn{5}{|c|}{ Average volumes over event date and date ranges } \\
\hline$t-60$ to $t-6$ & 1.15 & & 1.27 & \\
\hline $\mathrm{t}-5$ to $\mathrm{t}-1$ & 1.87 & & 1.66 & \\
\hline $\mathrm{t}$ & 1.31 & & 2.20 & \\
\hline $\mathrm{t}+1$ to $\mathrm{t}+15$ & 1.71 & & 1.53 & \\
\hline $\mathrm{T}+16$ to $\mathrm{t}+180$ & 1.49 & & 1.44 & \\
\hline
\end{tabular}


Table 11: Earnings Per Share for Additions One Year Pre- and Post-Event Split By Currency

\begin{tabular}{lrrrrrr}
\hline & \multicolumn{7}{c}{ Firms with Earnings in } & \\
& GBP & EUR & SK & DK & NK & SF \\
\hline$N$ & 149 & 129 & 25 & 12 & 10 & 9 \\
Mean EPS Pre-Event & 12.82 & 1.39 & 6.38 & 5.19 & 5.47 & 9.53 \\
Mean EPS Post-Event & 15.88 & 1.71 & 7.45 & 7.53 & 4.56 & 7.84 \\
\% Change in EPS & $24 \%$ & $23 \%$ & $17 \%$ & $45 \%$ & $-17 \%$ & $-18 \%$ \\
t-statistic for equality of means & 0.93 & 1.26 & 0.54 & 0.91 & 0.50 & 0.45 \\
p-value for t-statistic & 0.35 & 0.21 & 0.59 & 0.37 & 0.62 & 0.66 \\
\hline
\end{tabular}

Table 12: Earnings Per Share for Deletions One Year Pre- and Post-Event Split By Currency

\begin{tabular}{lrrr}
\hline & \multicolumn{3}{c}{ Firms with Earnings in } \\
& GBP & EUR & SK \\
\hline$N$ & 53 & 41 & 8 \\
Mean EPS Pre-Event & 8.75 & 1.17 & 13.58 \\
Mean EPS Post-Event & 10.21 & 1.18 & 16.38 \\
$\%$ Change in EPS & $17 \%$ & $1 \%$ & $21 \%$ \\
t-statistic for equality of means & 0.67 & 0.02 & 0.45 \\
p-value for t-statistic & 0.50 & 0.98 & 0.66 \\
\hline
\end{tabular}


Figure 1: Cumulative Average Abnormal Returns (\%) from Day t-5 to day $t+15$ for Additions Sample with Outliers Removed

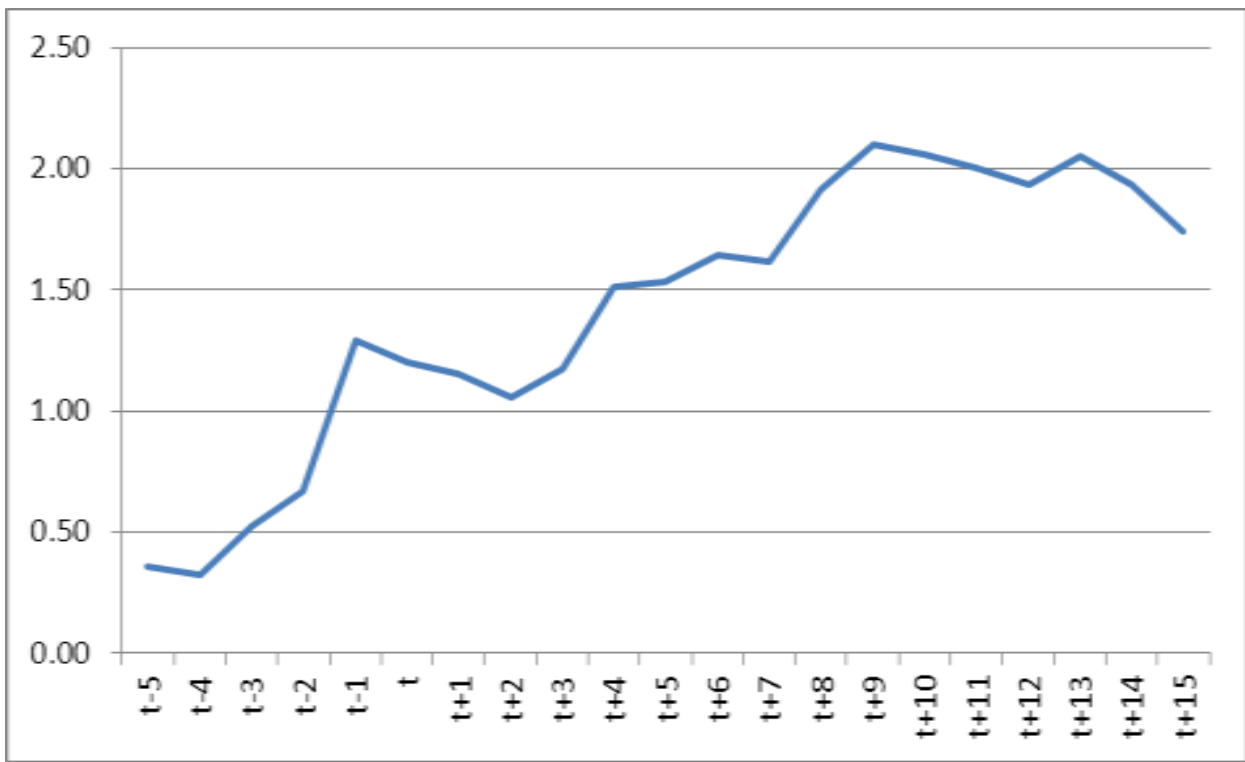

Figure 2: Graph of Cumulative Average Abnormal Returns (\%) from Day t-5 to day $t+15$ for Deletions Sample with Outliers Removed

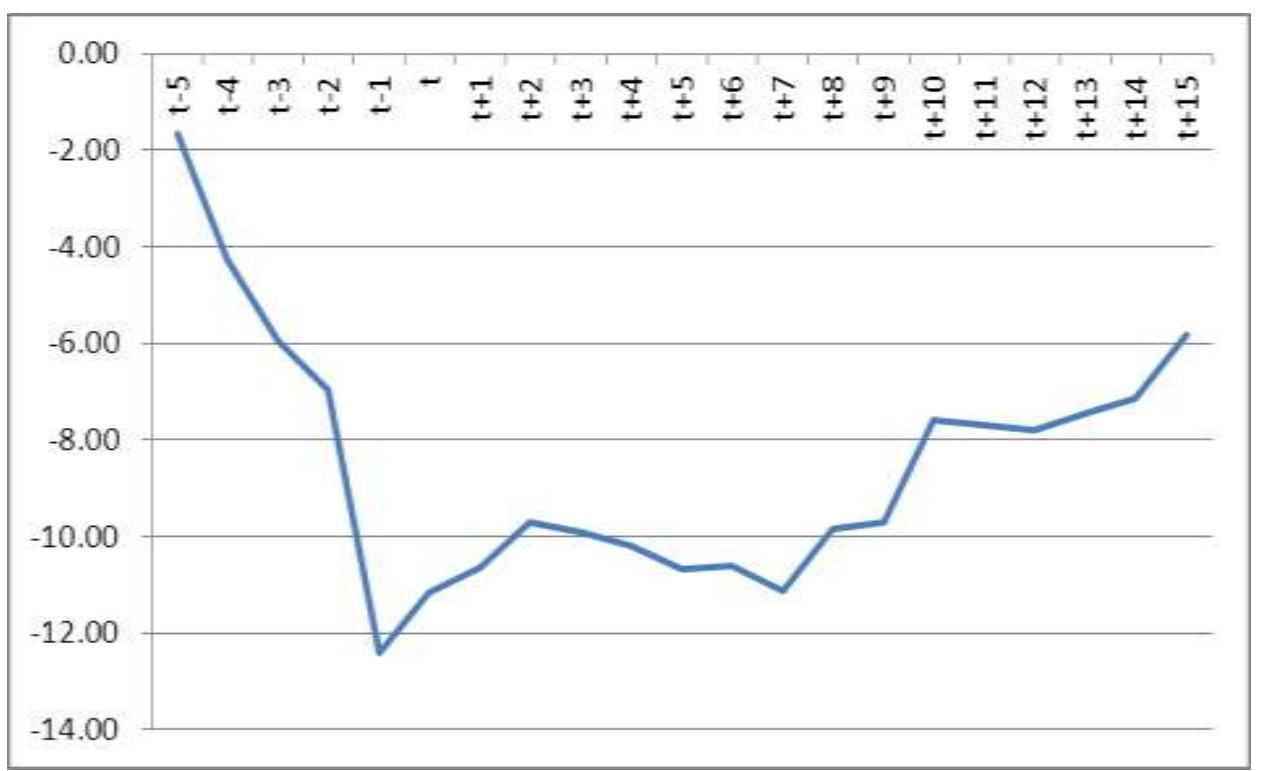


Figure 3: Volumes and Abnormal Returns for Additions Relative to EPRA Benchmark, Outliers Removed

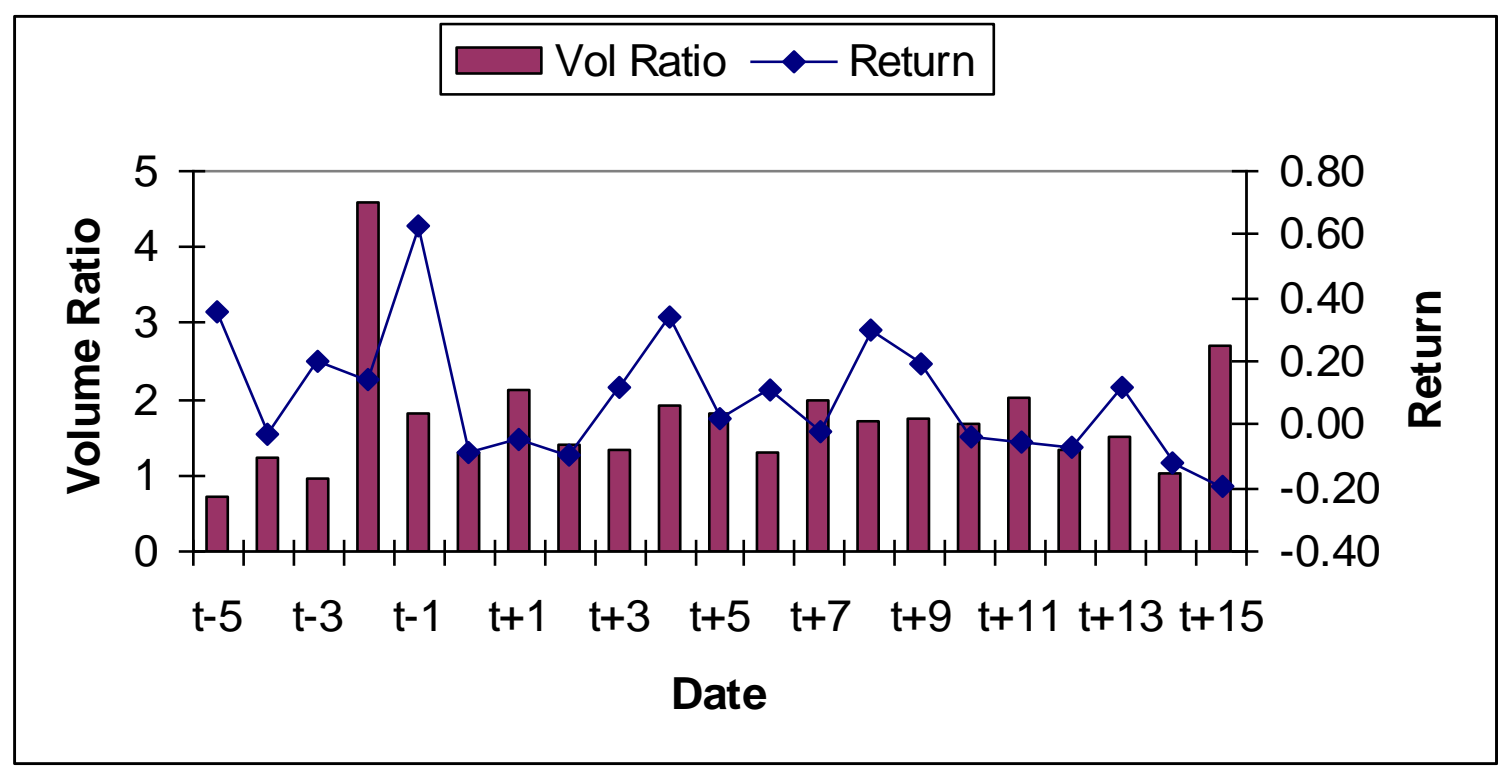

Figure 4: Volumes and Abnormal Returns for Deletions Relative to EPRA Benchmark, Outliers Removed

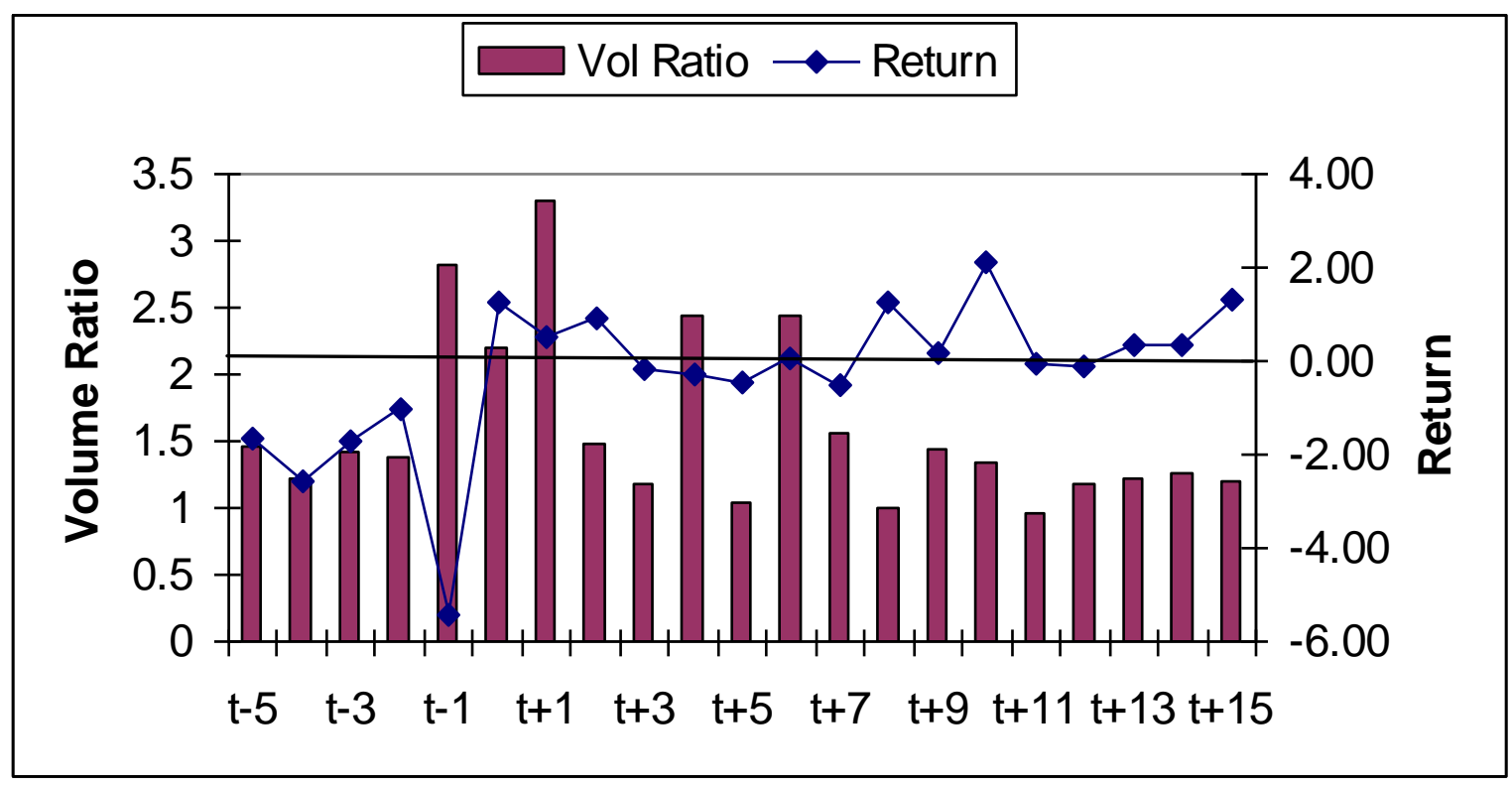


Figure 5: Volume Ratios on days t-5 to $t+15$ for Additions and Deletions

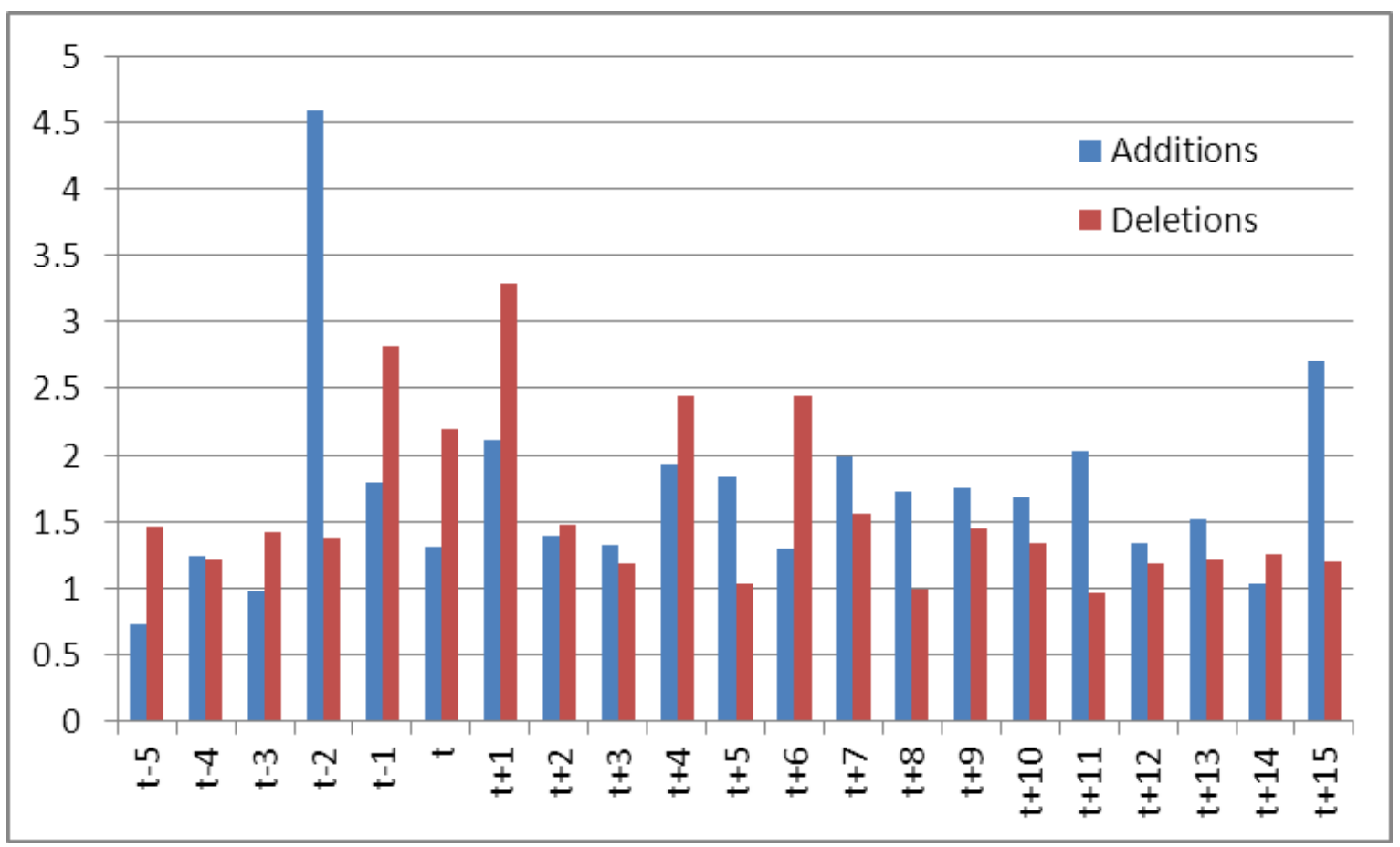




\section{Endnotes:}

${ }^{1}$ The size of the index effect, and consequently the amount of money to be made from its existence, may also depend upon the value of funds tracking a particular benchmark.

${ }^{2}$ REITs are tax transparent entities. Whilst the detailed regulatory structure varies across markets, in the majority of cases REITs have to comply with a number of restrictions in order for their dividend payments to be exempt from corporate tax. In most countries these restrictions revolve around a minimum dividend payout ratio and the imposition of constraints concerning the proportion of the firm's assets and income derived from real estate activity. Some countries also impose limitations in areas such as gearing, development activity and international operations.

${ }^{3}$ More specifically, these are known as the FTSE-EPRA NAREIT indices.

${ }^{4}$ However, even these indices may experience an imbalance between the number of additions and deletions due to the fact that most index re-compositions are driven by the event of deletions that are either acquired or bankrupt and hence they are not considered as "pure" deletions and need to be excluded from the sample.

${ }^{5}$ The non-parametric binomial Z-test is also performed in some studies to test the significance of the percentage of firms that have a positive abnormal return on the event days. However, we do not implement it here due to its low power.

${ }^{6}$ This analysis uses the average relative (stock-to-index) volume ratio over the estimation period instead of the average stock's trading volume divided by the average benchmark index trading volume over the same period. This amendment was proposed by Goodacre\& Lawrence (1994) as a volume ratio with improved characteristics.

${ }^{7}$ A post-inclusion estimation period is not needed in the case of trading activity. The price performance might have improved before the event, due to the potentially better performance of the firm but there is no evidence of increased liquidity for the stock. Therefore, the bias mentioned in the previous section does not apply to the volume figures, according to the literature.

${ }^{8}$ We only employ two size-sorted portfolios for the deletions sample since it is too small to split into three parts and still expect to obtain reliable results.

${ }^{9}$ If we employ abnormal returns constructed using the single index model to measure the returns as opposed to the raw returns in order to remove any effect of changing volatility in the market as a whole over the sample period, we obtain almost identical results, with variance ratios of 1.04 and 1.15 for additions and deletions respectively (as opposed to 1.01 and 1.14 for the raw returns).

${ }^{10}$ The figures are also uncharacteristically high on days $t+11$ and $t+15$, but we attribute these to events unrelated to index changes and therefore do not discuss them further; however, reassuringly, neither are as high as the figure of 4.6 on day $t-2$.

${ }^{11}$ It would be of interest to try to identify whether those trading before the event were mainly arbitrageurs and those trading on and immediately after were index funds; however, this would require information on the identification of specific counterparties which we do not have access to.

${ }^{12}$ Only a small number of papers have considered the impact of volume on the dynamics of the listed real estate market, and these have all focused on the US market (Cotter \& Stevenson, 2008; Hung \& Glascock, 2010; Akimov et al.,2012). 